\title{
Clinical significance of long non-coding RNA HOTTIP in early-stage non-small-cell lung cancer
}

Alfons Navarro ${ }^{1 *} \mathbb{D}$, Jorge Moises², Sandra Santasusagna', Ramon M. Marrades², Nuria Viñolas ${ }^{3}$, Joan J. Castellano ${ }^{1}$, Jordi Canals ${ }^{1}$, Carmen Muñoz ${ }^{1}$, José Ramírez ${ }^{4}$, Laureano Molins ${ }^{5}$ and Mariano Monzo ${ }^{1}$

\begin{abstract}
Background: HOTTIP, a long non-coding RNA located in the HOXA cluster, plays a role in the patterning of tissues with mesodermal components, including the lung. Overexpression of HOXA genes, including HOTTIP, has been associated with a more aggressive phenotype in several cancers. However, the prognostic impact of HOTTIP has not yet been explored in non-small-cell lung cancer (NSCLC). We have correlated HOTTIP expression with time to relapse (TTR) and overall survival (OS) in early-stage NSCLC patients.

Methods: Ninety-nine early-stage NSCLC patients who underwent surgical resection in our center from June 2007 to November 2013 were included in the study. Mean age was 66; 77.8\% were males; 73.7\% had stage I disease; and $55.5 \%$ had adenocarcinoma. A validation data set comprised stage I-II patients from The Cancer Genome Atlas (TCGA) Research Network.

Results: HOTTIP was expressed in all tumor samples and was overexpressed in squamous cell carcinoma $(p=0.007)$ and in smokers $(p=0.018)$. Patients with high levels of HOTTIP had shorter TTR (78.3 vs 58 months; $p=0.048$ ) and shorter OS (81.2 vs 61 months; $p=0.023$ ) than those with low levels. In the multivariate analysis, HOTTIP emerged as an independent prognostic marker for TTR (OR: 2.05, 95\%Cl: 1-4.2; $p=0.05$ ), and for OS (OR: 2.31, 95\%Cl: 1.04-5.1; $p=0.04)$. HOTTIP was validated as a prognostic marker for OS in the TCGA adenocarcinoma cohort $(p=0.025)$. Moreover, we identified a 1203-mRNA and a 61-miRNA signature that correlated with HOTTIP expression.
\end{abstract}

Conclusions: The IncRNA HOTTIP can be considered a prognostic biomarker in early-stage NSCLC.

Keywords: HOTTIP, NSCLC, Early-stage, Overall survival, Lung cancer, IncRNAs

\section{Background}

According to the American Cancer Society, in 2018, lung cancer will be the second most frequent cancer in the United States of America in both males and females (14 and 13\%, respectively, of all cancers) and the first leading cause of death by cancer (26 and 25\%, respectively) [1]. Non-small-cell lung cancer (NSCLC), the most frequent subtype, accounts for $85 \%$ of all lung cancers. Despite years of research, the prognosis for patients with NSCLC remains dismal, with a 5-year relative survival

\footnotetext{
* Correspondence: anavarroponz@ub.edu

${ }^{1}$ Molecular Oncology and Embryology Laboratory, Human Anatomy Unit, School of Medicine, University of Barcelona, IDIBAPS, Casanova 143, 08036 Barcelona, Spain

Full list of author information is available at the end of the article
}

rate of $18 \%$ for all stages combined (www.cancer.net). In the $30 \%$ of patients that debut with early-stage disease (stage I-II), the cornerstone of treatment is the surgical removal of the tumor. Moreover, in stage IB disease with a primary tumor $>4 \mathrm{~cm}$ and in stage II disease, adjuvant chemotherapy (usually cisplatin-vinorelbine) has proven to be beneficial, with a $4-5 \%$ absolute survival improvement at five years [2]. A large study including 1294 consecutive early-stage NSCLC patients who underwent surgery showed that after a median follow up of 35 months, $20 \%$ of patients had relapsed and $7 \%$ were diagnosed with a second primary lung cancer [3]. These data highlight the need to further investigate this disease and consolidate useful prognostic markers.

(c) The Author(s). 2019 Open Access This article is distributed under the terms of the Creative Commons Attribution 4.0 International License (http://creativecommons.org/licenses/by/4.0/), which permits unrestricted use, distribution, and reproduction in any medium, provided you give appropriate credit to the original author(s) and the source, provide a link to the Creative Commons license, and indicate if changes were made. The Creative Commons Public Domain Dedication waiver (http://creativecommons.org/publicdomain/zero/1.0/) applies to the data made available in this article, unless otherwise stated. 
$\mathrm{Up}$ to $70 \%$ of our genome is transcribed into non-coding RNAs (ncRNAs) that do not serve as templates for proteins. These ncRNAs are subdivided into two major groups: small ncRNAs (<200 nt) and long ncRNAs (lncRNAs) (> $200 \mathrm{nt}$ ) [4]. Although small ncRNAs, especially microRNAs (miRNAs), have been the most extensively studied [5], lncRNAs have recently emerged as worthy biomarkers, since their expression is highly cell type- and tissue-specific [6]. In NSCLC, several lncRNAs are involved in the carcinogenesis process, some of which have been associated with patient survival [7-9].

The $H O X$ family genes are known transcription factors with a key role in embryogenesis and carcinogenesis [10, 11]. Their expression is dysregulated in several cancers, including NSCLC [11-14]. In humans, $H O X$ genes are organized into four clusters (A, B, C, and D), which are located on different chromosomes [15]. Interestingly, several lncRNAs associated with $H O X$ genomic regions can participate in the regulation of $H O X$ genes and collaborate in their functions [16]. HOTTIP, also known as HOXA distal transcript antisense RNA, is an antisense lncRNA located in the HOXA cluster that coordinates the activation of several $5^{\prime} H O X A$ genes in vivo [17]. It is overexpressed in several cancers [18-20], including NSCLC, where its overexpression in vitro has been associated with increased proliferation and invasion of lung cancer cells through transcriptional regulation of $H O X A 13$ [21]. Moreover, HOTTIP overexpression has been associated with worse outcome in several tumors, including hepatocellular carcinoma [22], tongue squamous cell carcinoma [18], colorectal cancer [20], osteosarcoma [23], breast cancer [24], gastric cancer [19], and even small-cell lung cancer [25]. To date, however, the prognostic impact of HOTTIP expression levels in NSCLC has not been explored [26, 27].

In the present study, we have analyzed HOTTIP expression in a cohort of 99 patients with early-stage NSCLC who underwent surgical resection in our center and have correlated HOTTIP expression levels with overall survival (OS) and time to relapse (TTR).

\section{Methods}

\section{Patients}

A total of 99 early-stage NSCLC patients who underwent complete surgical resection in Hospital Clínic (Barcelona) from May 2007 to October 2013 were included in the study. Prospectively collected tumor tissues were stored in RNALater ${ }^{ø}$ (Ambion) at $-80^{\circ} \mathrm{C}$ until processing. Clinical data were recorded on admission: age, gender, smoking history, Eastern Cooperative Oncology Group (ECOG) performance status (PS), preoperative pulmonary function tests (PFT) and chronic obstructive pulmonary disease (COPD). COPD was defined as when forced expiratory volume in $1 \mathrm{~s}$ (FEV1) to forced vital capacity (FVC) ratio is below a fixed cutoff $(<70 \%)$. Type of surgical resection and pathological findings were also recorded, including tumor characteristics and the presence of emphysema (defined histopathologically in the resected non-tumoral tissue). All patient samples were studied by Sanger sequencing for mutations in TP53 (exons 5-8) and KRAS (codon 12-13), and only adenocarcinoma patients samples were studied for EGFR mutations (exons 19-21). The following primers were used: TP53 exon 5 Forward (F) 5'- GTTTCTTTGCTG CCGTCTTC-3', TP53 exon 5 Reverse (R) 5'-GAGC AATCAGTGAGGAATCAGA-3'; TP53 exon 6 F 5' -AG AGACGACAGGGCTGGTT-3', TP53 exon 6 R 5'-CT TAACCCCTCCTCCCAGAG-3'; TP53 exon $7 \mathrm{~F} 5^{\prime}$ TTGCCACAGGTCTCCCCAA-3', TP53 exon 7 R 5'-A GGGGTCAGAGGCAAGCAGA-3'; and TP53 exon $8 \mathrm{~F}$ 5'-GGGACAGGTAGGACCTGATTT-3', TP53 exon 8 R 5'-TAACTGCACCCTTGGTCTCC-3'; KRAS F 5'-T TAACCTTATGTGTGACATGTT-3', KRAS R 5'-AGA ATGGTCCTGCACCAGTAA-3'; EGFR exon $18 \mathrm{~F}$ 5'GCATGGTGAGGGCTGAGGT-3', EGFR exon $18 \mathrm{R}$ 5' -TGCAAGGACTCTGGGCTCC-3',EGFR exon $19 \mathrm{~F}$ 5' -TGCATCGCTGGTAACATCCA-3', EGFR exon $19 \mathrm{R}$ 5'-GAAAAGGTGGGCCTGAGGTT-3', EGFR exon 20 F 5'-TCCTTCTGGCCACCATGC-3', EGFR exon $20 \mathrm{R}$ 5' -TGGCTCCTTATCTCCCCTCC-3', EGFR exon $21 \mathrm{~F}$ 5' -ATGCAGAGCTTCTTCCCATGA-3', EGFR exon 21 R 5'-CAGGAAAATGCTGGCTGACC-3'.

All patients signed the written consent in accordance with the Declaration of Helsinki to use their samples in the present research. The Clinical Research Ethics Committee of the Hospital Clínic de Barcelona approved the study.

NSCLC patients from The Cancer Genome Atlas (TCGA) Research Network (RNAseq data; https://cancergenome.nih.gov) were used as a validation data set. Two cohorts were used: the Lung Adenocarcinoma (TCGA-LUAD) and the Lung Squamous Cell Carcinoma (TCGA-LUSC). The patient selection criteria were: stage I-II, Caucasian, minimum OS of 35 days, and available RNAseq data. Using these selection criteria, the validation cohorts included 91 adenocarcinomas from the TCGA-LUAD and 59 squamous cell carcinomas from the TCGA-LUSC cohort. The analysis was performed separately in each cohort.

\section{RNA extraction and IncRNA expression analysis}

Total RNA was purified from frozen tissue with TriZol ${ }^{\circ}$ Reagent (Life Technologies) as per manufacturer's specifications. cDNA was synthetized from $500 \mathrm{ng}$ of total RNA with The High Capacity cDNA Reverse Transcription Kit ${ }^{\circ}$ (Applied Biosystems). TaqMan assays (Life Technologies) were used to quantify HOTTIP (Hs00955374_s1) in a 7500 Real Time PCR device (Applied Biosystems). 
CDKN1B (Hs00153277_m1) was used as endogenous control, and the mean of the HOTTIP expression in the normal tissue was used as calibrator sample to apply the $2^{-\Delta \Delta \mathrm{Ct}}$ method.

\section{Statistics}

R v3.3 and IBM SPSS Statistics 22 were used for statistical analysis. TTR was calculated as the time between surgery and relapse or last follow-up and OS as the time between surgery and death from any cause or last follow-up. Kaplan-Meier survival curves and log-rank test were used for the survival analysis. All clinic-pathological factors with $p$-value $\leq 0.1$ in the univariate analysis were included in the Cox multivariate regression analyses. The Optimal cutoff for the analysis of the impact on survival of the HOTTIP expression was identified using the Maxstat package (R Statistical Package) and validated by the Kaplan-Meier test. Paired (when necessary) or non-paired t-tests were used for comparisons between two groups. The independent validation of the prognostic role of HOTTIP levels were performed using TANRIC [28] (http://ibl.mdanderson.org/tanric/_design/ basic/index.html) based upon data generated by the TCGA Research Network (http://cancergenome.nih.gov/).

\section{Results}

\section{Patients}

The main clinic-pathological characteristics of the patients are summarized in Table 1 . Briefly, the mean patient age was 66 years (range, 32-84), 77 patients (77.8\%) were male, $20(20.2 \%)$ had Eastern Cooperative Oncology Group (ECOG) performance status (PS) 0 and 79 (79.8\%) had PS 1. Seventy-three (60.2\%) patients were diagnosed in stage I disease. Adenocarcinoma histology was found in fifty-five (55.5\%) patients and 87 $(87.9 \%)$ were active or former smokers. Median follow-up time was 44 months (range, 8-98). After a follow-up of 98 months, 31 (31.3\%) patients experienced disease recurrence. Twenty-three patients (23.2\%) received adjuvant therapy after surgery (17 stage II and six stage IB). Thirty-three percent of the patients harbored TP53 mutations and 20\% harbored KRAS mutations. Adenocarcinoma patients with EGFR mutations $(29.8 \%)$ showed a trend towards shorter TTR $(p=0.09)$ and OS $(p=0.09)$.

\section{HOTTIP expression and clinical characteristics}

Patients with squamous cell carcinoma had significantly higher levels of HOTTIP than those with adenocarcinoma ( $p=0.007$; Fig. 1a). HOTTIP was also overexpressed in current and former smokers in comparison with never-smokers ( $p=0.02$; Fig. 1b) and in former smokers of $<15$ years compared to former smokers of $>15$ years although this difference was not significant (data not shown). Patients with PS 1 had higher levels of HOTTIP
Table 1 Main clinical characteristics of the patients

\begin{tabular}{|c|c|c|}
\hline Characteristics & Value & $\begin{array}{l}N=99 \\
N(\%)\end{array}$ \\
\hline \multirow[t]{2}{*}{ Sex } & Male & $77(77.8)$ \\
\hline & Female & $22(22.2)$ \\
\hline \multirow[t]{3}{*}{ Age, yrs. } & Mean (Range) & $66(32-84)$ \\
\hline & $<=65$ & $49(49.5)$ \\
\hline & $>65$ & $50(50.5)$ \\
\hline \multirow[t]{2}{*}{ ECOG PS ${ }^{a}$} & 0 & $20(20.2)$ \\
\hline & 1 & 79 (79.8) \\
\hline \multirow[t]{2}{*}{ Stage } & I & $73(73.7)$ \\
\hline & $\|$ & $26(26.3)$ \\
\hline \multirow[t]{3}{*}{$\mathrm{T}$} & 1 & $47(47.5)$ \\
\hline & 2 & $49(49.5)$ \\
\hline & 3 & $3(3)$ \\
\hline \multirow[t]{2}{*}{ N } & 0 & $88(88.9)$ \\
\hline & 1 & $11(11.1)$ \\
\hline \multirow[t]{3}{*}{ Histology } & Adenocarcinoma & $55(55.5)$ \\
\hline & Squamous cell carcinoma & $36(36.4)$ \\
\hline & Others & $8(8.1)$ \\
\hline \multirow[t]{3}{*}{ Type of surgery } & Lobectomy/bilobectomy & 89 (89.9) \\
\hline & Pneumonectomy & $4(4)$ \\
\hline & Atypical Resection ${ }^{\mathrm{b}}$ & $6(6.1)$ \\
\hline \multirow[t]{3}{*}{ Smoking history } & Current Smoker & $34(34.4)$ \\
\hline & Former Smoker & $53(53.5)$ \\
\hline & Never smoker & $12(12.1)$ \\
\hline \multirow[t]{2}{*}{ Adjuvant chemotherapy } & Yes & $23(23.2)$ \\
\hline & No & $76(76.8)$ \\
\hline \multirow[t]{2}{*}{ Relapse } & No & $68(68.7)$ \\
\hline & Yes & $31(31.3)$ \\
\hline \multirow[t]{3}{*}{ Emphysema } & Yes & $48(48.5)$ \\
\hline & No & $44(44.4)$ \\
\hline & Unknown & $7(7.1)$ \\
\hline \multirow[t]{2}{*}{$\mathrm{COPD}^{c}$} & Yes & $64(64.6)$ \\
\hline & No & $35(35.4)$ \\
\hline $\operatorname{DLCO}^{d}(\%)$ & Mean (Range) & $73.4(35-101)$ \\
\hline \multirow[t]{3}{*}{ Molecular features } & TP53 mutations & 31/94 (33) \\
\hline & KRAS mutations & 20/98 (20.4) \\
\hline & EGFR mutations ${ }^{\mathrm{e}}$ & 14/47 (29.8) \\
\hline
\end{tabular}

${ }^{\mathrm{a} E C O G}$ PS, Eastern Cooperative Oncology Group performance status

${ }^{b}$ Atypical resection refers to Wedge resection, a non-anatomic limited resection of a lung portion

${ }^{c} \mathrm{COPD}$, chronic obstructive pulmonary disease

${ }^{\mathrm{d}} \mathrm{DLCO}$, diffusing capacity of the lung for carbon monoxide

eEGFR mutational status was assessed only in adenocarcinoma patients

than those with PS $0(p=0.08)$. No association was observed between HOTTIP levels and TP53, KRAS or EGFR mutational status. 

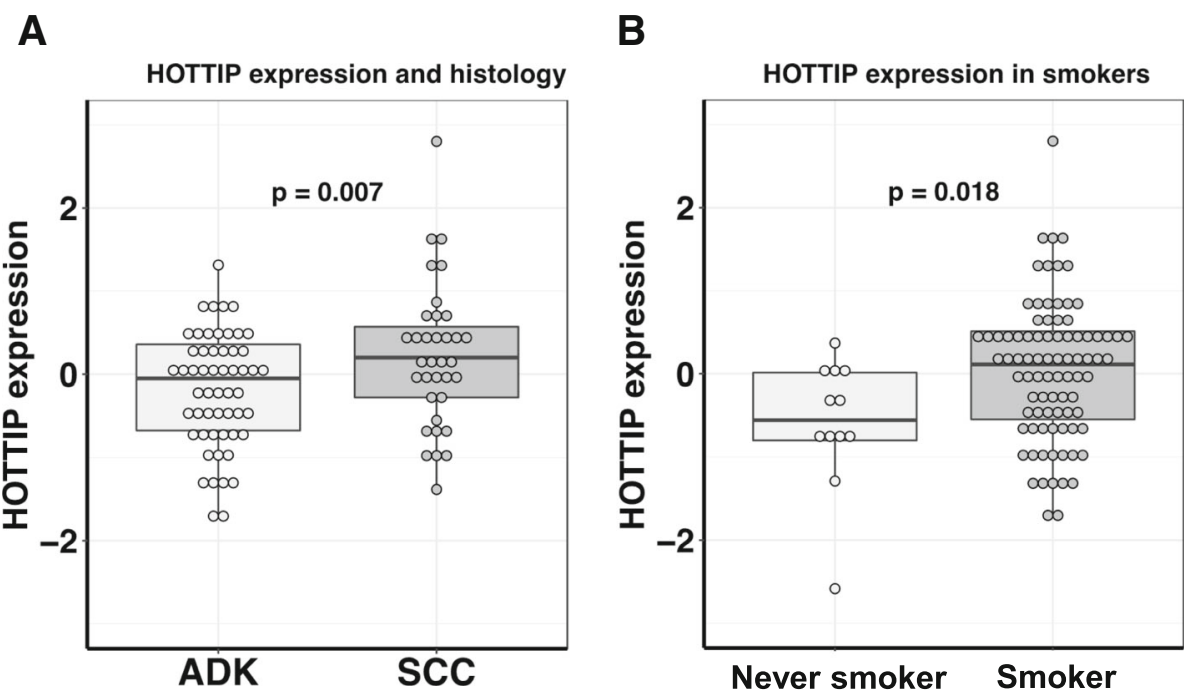

Fig. 1 HOTTIP expression according to (a) histology and (b) smoking status. ADK, adenocarcinoma; SCC, squamous cell carcinoma

\section{HOTTIP expression and clinical outcome}

HOTTIP was expressed in all samples. Using the cutoff identified by the Maxstat package of R, patients were included depending on HOTTIP expression level into the high $(n=43)$ or the low $(n=56)$ group. The cutoff identified coincided with the Mean + SD of HOTTIP expression in the normal tissue (Additional file 1: Figure S1). Patients with high levels of HOTTIP had shorter TTR (78.3 vs 58 months; $p=0.05)$ and shorter OS (81.2 vs 61 months; $p=0.02$ ) than those with low levels (Fig. 2).

The univariate Cox analysis for all clinical variables and for HOTTIP levels are shown in Table 2. In the multivariate analysis for TTR, including sex and HOTTIP levels, only HOTTIP levels emerged as a significant marker (Hazard ratio [HR]: 2.05; 95\% confidence interval $[\mathrm{CI}]: 1-4.22 ; p=0.05)$. The multivariate analysis for $\mathrm{OS}$, including sex, age, PS, smoking status, emphysema, and HOTTIP levels, identified age $>65$ (HR: 2.72; 95\%CI: 1.04-5.13; $p=0.01$ ) and HOTTIP levels (HR: 2.31, 95\%CI: $1.04-5.13 ; p=0.04)$ as independent prognostic markers (Table 3).

\section{Independent validation of HOTTIP prognostic impact using TCGA data}

Using TCGA data and the TANRIC web tool, we found that high levels of HOTTIP were associated with shorter OS $(p=0.025)$ in a cohort of 91 stage I-II patients with lung adenocarcinoma (Fig. 3a). However, the same analysis in the TCGA cohort of 59 stage I-II patients with squamous cell carcinoma of the lung showed no significant differences $(p=0.69$, Fig. 3b).

\section{A}

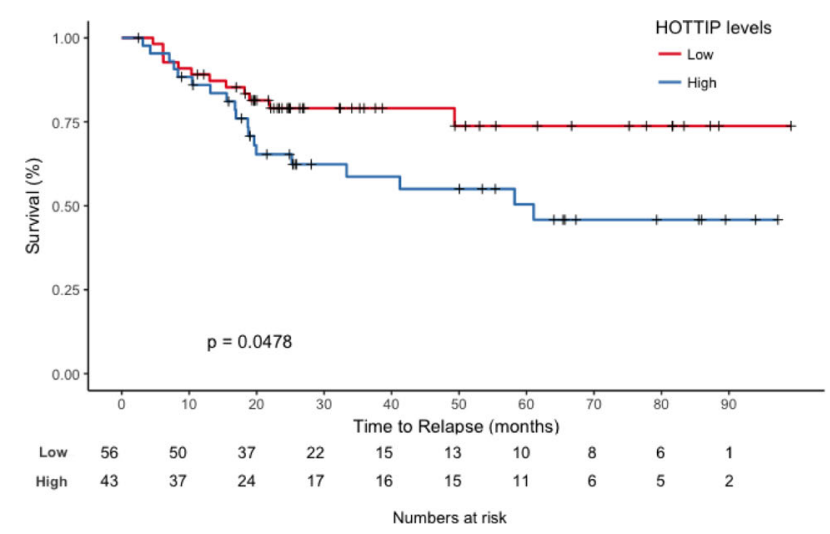

B

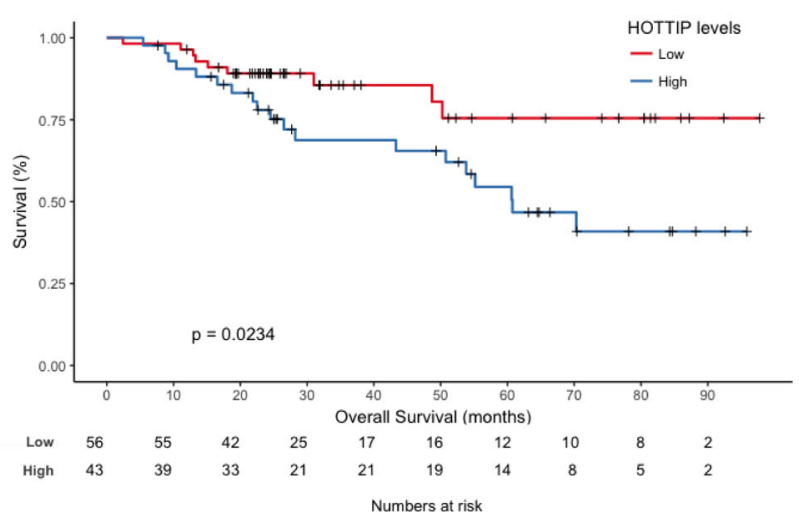

Fig. 2 a Time to relapse and (b) overall survival according to HOTTIP levels 
Table 2 Cox univariate analyses of time to relapse and overall survival

\begin{tabular}{|c|c|c|}
\hline & Hazard Ratio $(95 \% \mathrm{Cl})$ & $p$-value \\
\hline \multicolumn{3}{|l|}{ Time to Relapse } \\
\hline Male sex & 3.039 (0.924-9.999) & 0.067 \\
\hline Age $>65$ & $1.207(0.596-2.443)$ & 0.602 \\
\hline PS 1 & $1.738(0.607-4.972)$ & 0.303 \\
\hline Stage II & $0.888(0.397-1.989)$ & 0.773 \\
\hline T3 & $1.213(0.159-9.275)$ & 0.853 \\
\hline N1 & $1.142(0.399-3.272)$ & 0.805 \\
\hline Histology-Adenocarcinoma & $0.860(0.402-1.840)$ & 0.698 \\
\hline Type of surgery-Pneumonectomy & $4.812(0.494-46.847)$ & 0.176 \\
\hline Smoker & $1.295(0.632-2.656)$ & 0.480 \\
\hline Adjuvant chemotherapy-Yes & $0.890(0.382-2.072)$ & 0.787 \\
\hline Emphysema & $1.121(0.540-2.329)$ & 0.759 \\
\hline COPD & $1.131(0.532-2.403)$ & 0.749 \\
\hline TP53 mutated & $1.841(0.888-3.814)$ & 0.101 \\
\hline KRAS mutated & $1.217(0.544-2.721)$ & 0.633 \\
\hline EGFR mutated & $2.334(0.845-6.450)$ & 0.102 \\
\hline High HOTTIP levels & $2.047(0.992-4.224)$ & 0.053 \\
\hline \multicolumn{3}{|l|}{ Overall Survival } \\
\hline Male sex & $3.748(0.889-15.8)$ & 0.072 \\
\hline Age $>65$ & $2.628(1.185-5.829)$ & 0.017 \\
\hline PS 1 & $6.726(0.914-49.520)$ & 0.061 \\
\hline Stage II & $0.720(0.291-1.781)$ & 0.478 \\
\hline T3 & $1.486(0.192-11.507)$ & 0.705 \\
\hline N1 & $0.585(0.139-2.469)$ & 0.466 \\
\hline Histology Adenocarcinoma & $0.763(0.336-1.732)$ & 0.518 \\
\hline Type of surgery- Pneumonectomy & $1.515(0.213-10.797)$ & 0.678 \\
\hline Smoker & $0.387(0.156-0.959)$ & 0.040 \\
\hline Adjuvant chemotherapy- Yes & $1.082(0.459-2.549)$ & 0.857 \\
\hline Emphysema & $1.948(0.897-4.230)$ & 0.092 \\
\hline COPD & $1.115(0.504-2.467)$ & 0.788 \\
\hline TP53 mutated & $1.271(0.568-2.844)$ & 0.560 \\
\hline KRAS mutated & $1.124(0.477-2.646)$ & 0.789 \\
\hline EGFR mutated & $2.551(0.822-7.916)$ & 0.105 \\
\hline High HOTTIP levels & $2.442(1.1-5.418)$ & 0.028 \\
\hline
\end{tabular}

\section{Analysis of HOTTIP correlation with TCGA mRNA and miRNA data}

Using TANRIC and TCGA lung adenocarcinoma patients, we identified 1203 mRNAs and 61 miRNAs that significantly correlated with HOTTIP expression $(p<0.05)$. The most significant mRNA was HOXA13 $(\mathrm{r}=0.7, p<0.001)$. Moreover, other $H O X A$ genes were among the top 100 mRNAs, including HOXA9 ( $\mathrm{r}=0.51, p<0.001)$, HOXA11 $(\mathrm{r}=0.48, p<0.001)$, and HOXA10 $(\mathrm{r}=0.44, p<0.001)$.
Table 3 Multivariate analyses of time to relapse and overall survival

\begin{tabular}{lll}
\hline & Hazard Ratio $(95 \% \mathrm{Cl})$ & $p$-value \\
\hline Time to Relapse & & \\
Male sex & $2.71(0.82-8.99)$ & 0.10 \\
High HOTTIP expression & $2.05(1-4.22)$ & 0.05 \\
Overall Survival & & \\
Male sex & $3.25(0.76-13.84)$ & 0.11 \\
Age $>65$ & $2.72(1.23-6.04)$ & 0.01 \\
ECOG PS $1^{\text {a }}$ & $4.04(0.54-30.17)$ & 0.17 \\
Smoker & $0.60(0.06-5.3)$ & 0.66 \\
Emphysema & $1.5(0.68-3.34)$ & 0.32 \\
High HOTTIP expression & $2.31(1.04-5.13)$ & 0.04 \\
\hline aECOG PS, Eastern Cooperative Oncology Group performance status &
\end{tabular}

The Induced Network Module Analysis tool from Consensus PathDB (http://cpdb.molgen.mpg.de/CPDB) showed that most of the genes whose expression correlated with HOTTIP were closely related to the HOX gene network (Fig. 4a). One of the most significant miRNAs identified was miR-196b $(r=0.44, p<0.001)$, which is the only miRNA located in the HOXA genomic region. We then used miR-Path v.3 [29] to study the putative pathways regulated by this HOTTIP-miRNA signature and identified 49 KEGG pathways $(p<0.05)$. The most significant pathway identified was the Hippo signaling pathway $(p<0.001)$, where 86 genes are Tarbase-validated targets of 28 of the miRNAs included in the signature. Other relevant KEGG pathways identified were the TGF-beta signaling pathway, Cell cycle, Signaling pathways regulating pluripotency of stem cells, Wnt signaling pathway and p53 signaling pathway (Fig. 4b). Additional file 2 includes the list of the top 100 mRNAs and all 61 miRNAs identified.

\section{Discussion}

HOTTIP is one of the IncRNAs located in the HOXA genomic region of chromosome 7 . The $H O X$ genes are crucial transcription factors that determine the identity of cells and tissues during embryogenesis [30]. In adult tissues, $H O X$ genes play a role in normal hematopoiesis regulation and are overexpressed in hematological [31] and solid cancers [10], including NSCLC [14]. Specifically, the HOXA gene cluster, where HOTTIP is found, plays a critical role in the patterning of tissues with mesodermal components, such as the lung, and in the regulation of epithelial-mesenchymal interactions [32]. HOTTIP has been related to tumor metastasis through induction of epithelial-mesenchymal transition [33].

In the present study, we have examined the role of HOTTIP as a prognostic factor in early-stage NSCLC patients treated with curative surgery and found that 


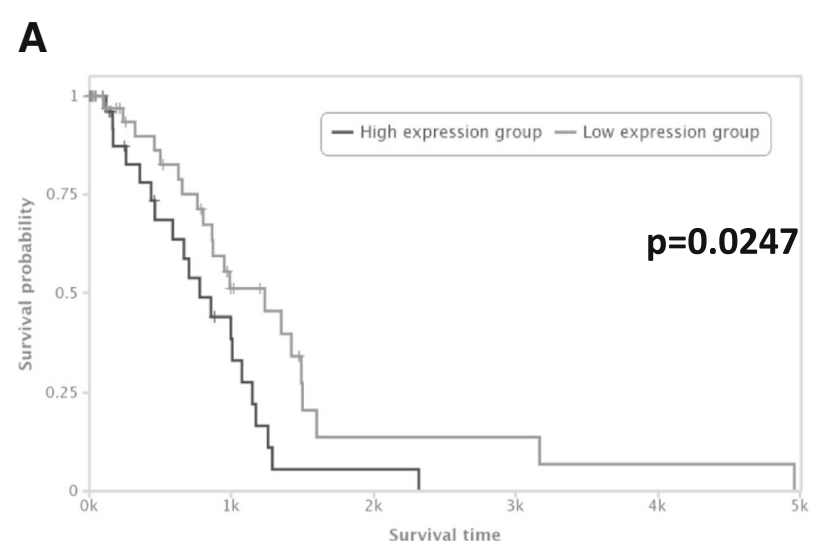

B

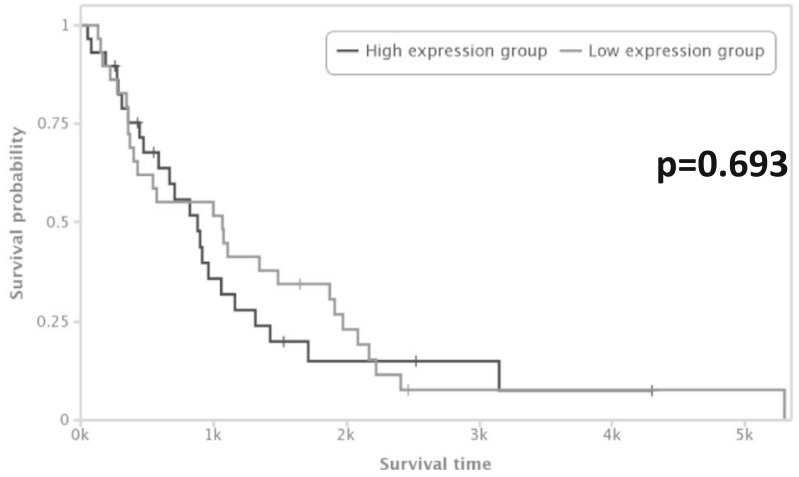

Fig. 3 Independent validation of HOTTIP as prognostic marker in (a) TCGA lung adenocarcinoma (LUAD) patients and (b) TCGA squamous cell carcinoma (LUSC) patients

patients with higher levels of HOTTIP had shorter TTR and shorter OS than patients with low levels. Moreover, HOTTIP emerged as an independent prognostic factor in the multivariate analysis. The prognostic role of HOTTIP levels has been described in several cancers $[19,20,22-25]$ and analyzed in several meta-analyses [26, 27, 34-36], which concluded that high HOTTIP expression in cancer patients is associated with poor clinical outcome. However, to the best of our knowledge, ours is the first study to provide evidence that HOTTIP impacts prognosis in NSCLC.

Additionally, we validated our findings on the prognostic value of HOTTIP levels in another patient population using TGCA data and the TANRIC webtool [28], showing that HOTTIP impacts prognosis in NSCLC patients with adenocarcinoma but not in those with squamous cell carcinoma. In our cohort, tumor HOTTIP levels were significantly overexpressed in squamous cell carcinoma compared to adenocarcinoma. While this may suggest that the prognostic impact of HOTTIP could differ between the main histological subtypes, the sub-analysis in the different histological subtypes in our cohort (Additional file 3: Figure S2) did not produce conclusive results, probably due to the small size of the sub-groups (55 adenocarcinomas and 36 squamous cell carcinomas). However, in both cases, high HOTTIP levels were associated with shorter TTR and shorter OS. Previous studies have reported that disordered patterns of HOX gene expression - specifically, HOXA1, HOXA5 and HOXA10 - are involved not only in the development of NSCLC but also in histological diversity [13]. HOTTIP is located close to the $3^{\prime}$ region of HOXA10 and we observed a positive correlation in the expression of the two genes in the in silico analysis of TCGA data.

We also observed a significant upregulation of HOTTIP in current and former smokers in comparison with never smokers. An in vivo study showed that cigarette smoke increases mRNA and protein levels of HOXA in endometrial cells [37]. Interestingly, in our cohort, former smokers of $>15$ years showed lower levels of HOTTIP than former smokers of $<15$ years although this difference was not significant.

Finally, since regulatory interactions between lncRNAs, mRNAs and miRNAs have been described [38], we explored a possible association between the mRNAs and miRNAs whose expression correlated with HOTTIP according to TGCA data on adenocarcinoma NSCLC analyzed with TANRIC. This analysis identified a signature of 1203 mRNAs and 61 miRNAs. When we focused on the top 100 mRNAs, we observed that most of the genes whose mRNA expression correlated with HOTTIP expression were closely related to the HOX gene network, including HOXA9, HOXA10, HOXA11, HOXA13, and other $H O X$ cluster members, such as $H O X B 13$. Several studies have reported that interactions between HOTTIP and some of these $H O X$ genes promote tumorigenesis. In prostate cancer, HOTTIP forms a complex with the transcription factor TWIST1 and with WDR5 and produces upregulation of HOXA9 levels through chromatin regulation which correlates with an aggressive cellular phenotype [39]. Moreover, HOTTIP modulates cancer stem cell properties by binding WDR5 and activating HOXA9, which enhances the $\mathrm{Wnt} / \beta$-catenin pathway in prostate cancer stem cells [40]. In pancreatic cancer cells, HOTTIP regulates HOXA10, HOXB2, HOXA11, HOXA9 and HOXA1, but not HOXA13 [41]. However, HOTTIP and HOXA13 have been associated with disease progression and worse outcome in hepatocellular carcinoma [22], with progression and gemcitabine resistance in pancreatic cancer [42], and with tumorogenesis and metastasis in esophageal squamous carcinoma [43] and gastric cancer [44]. In line with our results in NSCLC patient samples, these studies have shown that HOTTIP upregulation is associated with increased levels of HOXA13. In contrast, 


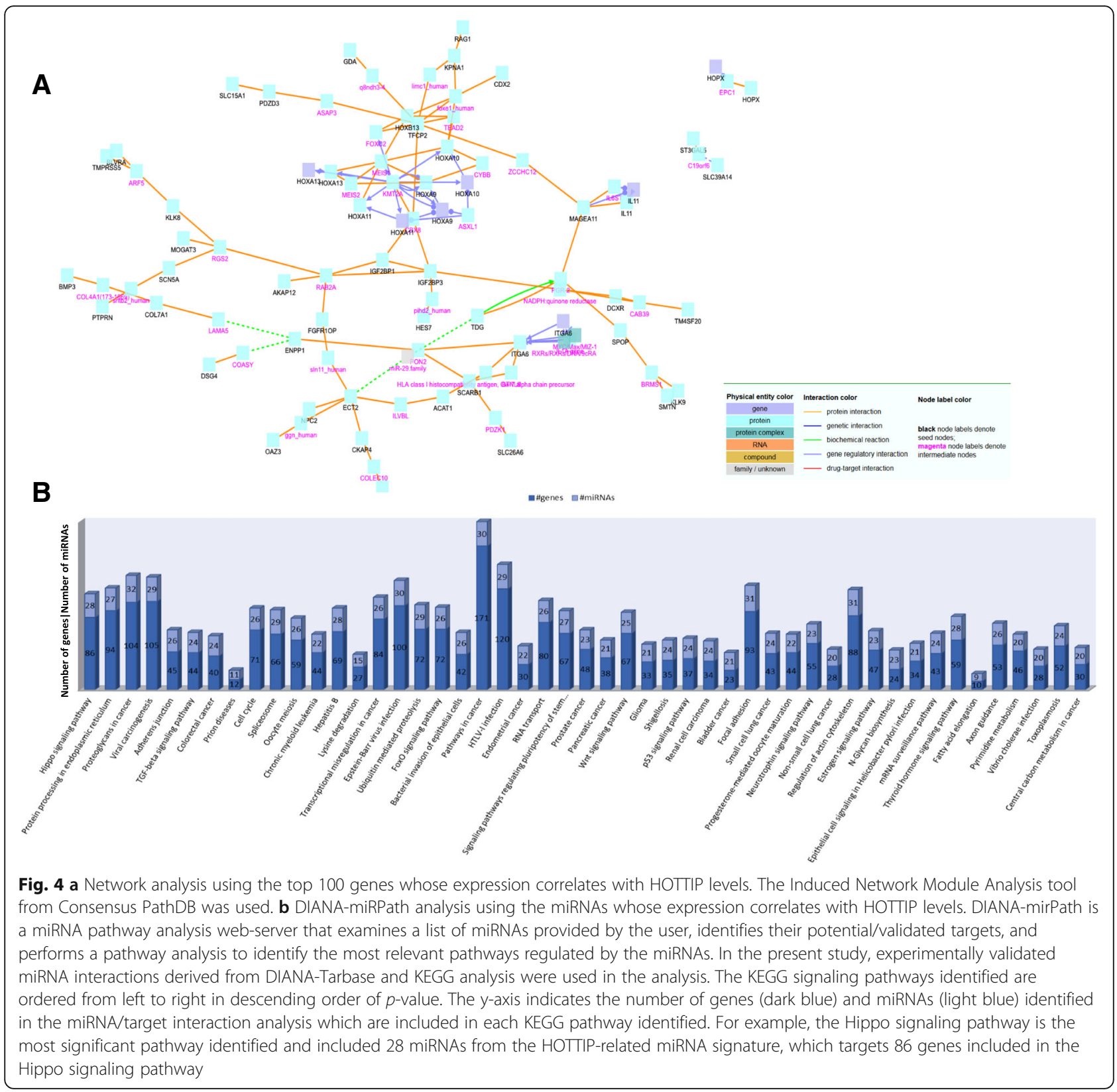

however, an in vitro study in the A549 NSCLC cell line showed that silencing HOTTIP led to increased HOXA13 levels [21]. Although this study included only one cell line and did not analyze the correlation between HOXA13 and HOTTIP in patient samples, it showed that HOTTIP acts as an oncogene, regulating apoptosis, proliferation, and migration in NSCLC. Another study, by Zhang et al., also reported the role of HOTTIP as oncogene in A549 through regulation of the AKT signaling pathway. The authors showed that the overexpression of HOTTIP enhanced proliferation and paclitaxel resistance [45].

Further studies are needed to clarify this interaction, including analyses in other NSCLC cell lines.
Interestingly, the network analysis also identified an additional node that included HOXP, a transcription factor related to alveolar differentiation, whose suppression has been linked to increased invasiveness in adenocarcinoma lung cancer [46]. There was a negative correlation between HOXP and HOTTIP levels, which could explain the more aggressive phenotype we have observed in patients with high HOTTIP levels.

When we explored the miRNAs in the 61-miRNA signature identified in the TANRIC analysis, we found a positive correlation with miR-196b, located in the distal part of the same HOXA cluster, and with miR-196a-1, located in the $H O X B$ cluster. The study of the potential 
pathways regulated by the miRNA signature showed the importance of the Hippo signaling pathway, which has previously been shown to be altered in NSCLC [47].

\section{Conclusions}

Our findings provide the first indication that HOTTIP may be a prognostic biomarker in NSCLC. In line with the prognostic impact of HOTTIP levels in other cancers, high levels of HOTTIP correlated with worse TTR and worse OS in our early-stage NSCLC patients. HOTTIP may be useful for the identification of resected NSCLC patients at high risk of relapse. Further investigation in a prospective study is warranted to validate these findings and to examine potential HOTTIP-based therapeutic approaches.

\section{Additional files}

Additional file 1: Figure S1. (A) Time to relapse and (B) overall survival according to HOTTIP levels in adenocarcinoma patients. (C) Time to relapse and (D) overall survival according to HOTTIP levels in squamous cell carcinoma patients. (PPTX $57 \mathrm{~kb}$ )

Additional file 2: Excel file with the results of the analysis of HOTTIP correlation with TCGA data that includes 2 sheets: mRNAs sheet, which includes the list of the top 100 mRNAs; and miRNAs sheet with all 61 miRNAs identified. (XLSX $19 \mathrm{~kb}$ )

Additional file 3: Figure S2. Bar plot showing the 99 patients ordered by HOTTIP expression level. An arrow shows the mean HOTTIP expression in the normal tissue and the cutoff used to classify the patients in high or low expression. The cutoff coincides with the Mean + SD of HOTTIP expression in the normal tissue. (PPTX $104 \mathrm{~kb}$ )

\section{Abbrebiations}

ECOG: Eastern Cooperative Oncology Group; IncRNAs: long non-coding RNAs; miRNAs: microRNAs; ncRNAs: non-coding RNAs; NSCLC: Non-small-cell lung cancer; OR: Odds ratio; OS: Overall survival; PS: Performance status; TCGA: The Cancer Genome Atlas; TTR: Time to relapse

\section{Acknowledgements}

Not applicable.

\section{Funding}

This work was supported by grants from AECC-Catalunya 2017 (AN), SAF2017-88606-P (AN) from the Ministry of Economy and Competition (MINECO) Co-financed with the European Union FEDER funds and SDCSD from the Universitat de Barcelona (MM). SS, JC and SM are APIF fellows of the Universitat de Barcelona. None of the funding bodies had any role in the design of the study and collection, analysis, and interpretation of data, or in writing the manuscript.

\section{Availability of data and materials}

The datasets used and/or analyzed during the current study are available from the corresponding author upon reasonable request.

\section{Authors' contributions}

AN designed the study, analyzed the data and wrote the manuscript draft; JM, SS, JJC, JC, CM have been involved in collection and assembly of data and interpretation of the results; JM, RMM, NV, JR, LM, MM collected clinical data and reviewed critically the manuscript. All authors approved the final version of the manuscript.

\section{Ethics approval and consent to participate}

Approval for the study was obtained from the Clinical Research Ethics Committee of the Hospital Clínic de Barcelona, and written informed consent was obtained from each participant in accordance with the Declaration of Helsinki.

\section{Consent for publication}

Not applicable.

\section{Competing interests}

The authors declare that they have no competing interests.

\section{Publisher's Note}

Springer Nature remains neutral with regard to jurisdictional claims in published maps and institutional affiliations.

\section{Author details}

${ }^{1}$ Molecular Oncology and Embryology Laboratory, Human Anatomy Unit, School of Medicine, University of Barcelona, IDIBAPS, Casanova 143, 08036 Barcelona, Spain. ${ }^{2}$ Department of Pneumology, Institut Clínic de Respiratori (ICR), Hospital Clínic de Barcelona, University of Barcelona, IDIBAPS, CIBER de Enfermedades Respiratorias (CIBERES), Barcelona, Spain. ${ }^{3}$ Department of Medical Oncology, Institut Clínic Malalties Hemato-Oncològiques (ICMHO), Hospital Clínic de Barcelona, University of Barcelona, IDIBAPS, Barcelona, Spain. ${ }^{4}$ Department of Pathology, Centro de Diagnóstico Biomédico (CDB), Hospital Clínic de Barcelona, University of Barcelona, IDIBAPS, CIBERES, Barcelona, Spain. ${ }^{5}$ Department of Thoracic Surgery, Institut Clínic de Respiratori (ICR), Hospital Clínic de Barcelona, University of Barcelona, Barcelona, Spain.

Received: 27 October 2018 Accepted: 14 February 2019

Published online: 28 February 2019

\section{References}

1. Siegel RL, Miller KD, Jemal A. Cancer statistics, 2018. CA Cancer J Clin. 2018; 68(1):7-30.

2. Cortés ÁA, Urquizu LC, Cubero JH. Adjuvant chemotherapy in non-small cell lung cancer: state-of-the-art. Translational Lung Cancer Res. 2015:4(2):191

3. Lou F, Huang J, Sima CS, Dycoco J, Rusch V, Bach PB. Patterns of recurrence and second primary lung cancer in early-stage lung cancer survivors followed with routine computed tomography surveillance. J Thorac Cardiovasc Surg. 2013;145(1):75-82.

4. Esteller M. Non-coding RNAs in human disease. Nat Rev Genet. 2011; 12(12):861.

5. Romano G, Veneziano D, Acunzo M, Croce CM. Small non-coding RNA and cancer. Carcinogenesis. 2017;38(5):485-91.

6. Yan X, Hu Z, Feng Y, Hu X, Yuan J, Zhao SD, Zhang Y, Yang L, Shan W, He Q. Comprehensive genomic characterization of long non-coding RNAs across human cancers. Cancer Cell. 2015:28(4):529-40.

7. Zhan Y, Zang H, Feng J, Lu J, Chen L, Fan S. Long non-coding RNAs associated with non-small cell lung cancer. Oncotarget. 2017:8(40):69174.

8. Castellano JJ, Navarro A, Viñolas N, Marrades RM, Moises J, Cordeiro A, Saco A, Muñoz C, Fuster D, Molins L. LincRNA-p21 impacts prognosis in resected non-small cell lung Cancer patients through angiogenesis regulation. J Thorac Oncol. 2016;11(12):2173-82.

9. Díaz-Beyá M, Brunet S, Nomdedéu J, Pratcorona M, Cordeiro A, Gallardo D, Escoda L, Tormo M, Heras I, Ribera JM. The lincRNA HOTAIRM1, located in the HOXA genomic region, is expressed in acute myeloid leukemia, impacts prognosis in patients in the intermediate-risk cytogenetic category, and is associated with a distinctive microRNA signature. Oncotarget. 2015;6(31): 31613.

10. Bhatlekar S, Fields JZ, Boman BM. HOX genes and their role in the development of human cancers. J Mol Med. 2014;92(8):811-23.

11. Shah N, Sukumar S. The Hox genes and their roles in oncogenesis. Nat Rev Cancer. 2010;10(5):361

12. Calvo R, West J, Franklin W, Erickson P, Bemis L, Li E, Helfrich B, Bunn P, Roche J, Brambilla E. Altered HOX and WNT7A expression in human lung cancer. Proc Natl Acad Sci. 2000;97(23):12776-81.

13. Abe M, Hamada J-i, Takahashi O, Takahashi Y, Tada M, Miyamoto M Morikawa T, Kondo S, Moriuchi T. Disordered expression of HOX genes in human non-small cell lung cancer. Oncol Rep. 2006;15(4):797-802.

14. Plowright $L$, Harrington K, Pandha H, Morgan R. HOX transcription factors are potential therapeutic targets in non-small-cell lung cancer (targeting HOX genes in lung cancer). Br J Cancer. 2009;100(3):470. 
15. Hoegg S, Meyer A. Hox clusters as models for vertebrate genome evolution. Trends Genet. 2005;21 (8):421-4

16. Wang $Y$, Dang $Y$, Liu J, Ouyang $X$. The function of homeobox genes and IncRNAs in cancer. Oncol Lett. 2016;12(3):1635-41.

17. Wang KC, Yang YW, Liu B, Sanyal A, Corces-Zimmerman R, Chen Y, Lajoie BR, Protacio A, Flynn RA, Gupta RA. A long noncoding RNA maintains active chromatin to coordinate homeotic gene expression. Nature. 2011; 472(7341):120

18. Zhang H, Zhao L, Wang Y-X, Xi M, Liu S-L, Luo L-L. Long non-coding RNA HOTTIP is correlated with progression and prognosis in tongue squamous cell carcinoma. Tumor Biol. 2015;36(11):8805-9.

19. Ye H, Liu K, Qian K. Overexpression of long noncoding RNA HOTTIP promotes tumor invasion and predicts poor prognosis in gastric cancer. OncoTargets Ther. 2016;9:2081.

20. Ren Y-K, Xiao Y, Wan X-B, Zhao Y-Z, Li J, Li Y, Han G-S, Chen X-B, Zou Q-Y, Wang G-C. Association of long non-coding RNA HOTTIP with progression and prognosis in colorectal cancer. Int J Clin Exp Pathol. 2015;8(9):11458.

21. Sang Y, Zhou F, Wang D, Bi X, Liu X, Hao Z, Li Q, Zhang W. Up-regulation of long non-coding HOTTIP functions as an oncogene by regulating HOXA13 in non-small cell lung cancer. Am J Transl Res. 2016;8(5):2022.

22. Quagliata L, Matter MS, Piscuoglio S, Arabi L, Ruiz C, Procino A, Kovac M, Moretti F, Makowska Z, Boldanova T. Long noncoding RNA HOTTIP/HOXA13 expression is associated with disease progression and predicts outcome in hepatocellular carcinoma patients. Hepatology. 2014;59(3):911-23.

23. Li F, Cao L, Hang D, Wang F, Wang Q. Long non-coding RNA HOTTIP is upregulated and associated with poor prognosis in patients with osteosarcoma. Int J Clin Exp Pathol. 2015;8(9):11414.

24. Yang Y, Qian J, Xiang Y, Chen Y, Qu J. The prognostic value of long noncoding RNA HOTTIP on clinical outcomes in breast cancer. Oncotarget. 2017:8(4):6833.

25. Sun Y, Zhou Y, Bai Y, Wang Q, Bao J, Luo Y, Guo Y, Guo L. A long noncoding RNA HOTTIP expression is associated with disease progression and predicts outcome in small cell lung cancer patients. Mol Cancer. 2017; 16(1):162.

26. Jin $N$, Yang $L Y, X u Z P$. Long non-coding RNA HOTTIP is able to predict poor prognosis in various neoplasms: a meta-analysis. Mol Clin Oncol. 2017;7(2): 263-6.

27. Fan Y, Yan T, Chai Y, Jiang Y, Zhu X. Long noncoding RNA HOTTIP as an independent prognostic marker in cancer. Clin Chim Acta. 2017;482:224-30.

28. Li J, Han L, Roebuck P, Diao L, Liu L, Yuan Y, Weinstein JN, Liang H. TANRIC: an interactive open platform to explore the function of IncRNAs in cancer. Cancer Res. 2015;75(18):3728-37.

29. Vlachos IS, Zagganas K, Paraskevopoulou MD, Georgakilas G, Karagkouni D, Vergoulis T, Dalamagas T, Hatzigeorgiou AG. DIANA-miRPath v3. 0: deciphering microRNA function with experimental support. Nucleic Acids Res. 2015:43(W1):W460-6.

30. limura T, Pourquié O. Hox genes in time and space during vertebrate body formation. Develop Growth Differ. 2007:49(4):265-75.

31. Eklund EA. The role of HOX genes in malignant myeloid disease. Curr Opin Hematol. 2007;14(2):85-9.

32. Di-Poï N, Koch U, Radtke F, Duboule D. Additive and global functions of HoxA cluster genes in mesoderm derivatives. Dev Biol. 2010;341 (2):488-98.

33. Chen X, Han H, Li Y, Zhang Q, Mo K, Chen S. Upregulation of long noncoding RNA HOTTIP promotes metastasis of esophageal squamous cell carcinoma via induction of EMT. Oncotarget. 2016;7(51):84480.

34. Li W, Li N, Kang X, Shi K, Chen Q. Prognostic value of the long noncoding RNA HOTTIP in human cancers. Oncotarget. 2017;8(35):59563.

35. Hu L, Li M, Ding Y, Pu L, Liu J, Xiong S. Long non-coding RNA HOTTIP, a novel potential prognostic marker in cancers; 2017.

36. Liu F-T, Xue Q-Z, Zhang Y, Hao T-F, Luo H-L, Zhu P-Q. Long non-coding RNA HOXA transcript at the distal tip as a putative biomarker of metastasis and prognosis: a meta-analysis. Clin Lab. 2016;62(11):2091-8.

37. Zhou Y, Jorgensen EM, Gan Y, Taylor HS. Cigarette smoke increases progesterone receptor and homeobox A10 expression in human endometrium and endometrial cells: a potential role in the decreased prevalence of endometrial pathology in smokers. Biol Reprod. 2011;84(6): 1242-7.

38. Paraskevopoulou MD, Hatzigeorgiou AG. Analyzing miRNA-IncRNA interactions. Methods Mol Biol. 2016;1402:271-86. https://doi.org/10.1007/ 978-1-4939-3378-5_21.
39. Malek R, Gajula RP, Williams RD, Nghiem B, Simons BW, Nugent K, Wang H, Taparra K, Lemtiri-Chlieh G, Yoon AR. TWIST1-WDR5-Hottip regulates Hoxa9 chromatin to facilitate prostate cancer metastasis. Cancer Res. 2017;77(12): 3181-93.

40. Fu Z, Chen C, Zhou Q, Wang Y, Zhao Y, Zhao X, Li W, Zheng S, Ye H, Wang L. LncRNA HOTTIP modulates cancer stem cell properties in human pancreatic cancer by regulating HOXA9. Cancer Lett. 2017;410:68-81.

41. Cheng Y, Jutooru I, Chadalapaka G, Corton JC, Safe S. The long non-coding RNA HOTTIP enhances pancreatic cancer cell proliferation, survival and migration. Oncotarget. 2015;6(13):10840

42. Li Z, Zhao X, Zhou Y, Liu Y, Zhou Q, Ye H, Wang Y, Zeng J, Song Y, Gao W. The long non-coding RNA HOTTIP promotes progression and gemcitabine resistance by regulating HOXA13 in pancreatic cancer. J Transl Med. 2015; 13(1):84.

43. Lin C, Wang Y, Zhang S, Yu L, Guo C, Xu H. Transcriptional and posttranscriptional regulation of HOXA13 by IncRNA HOTTIP facilitates tumorigenesis and metastasis in esophageal squamous carcinoma cells. Oncogene. 2017;36(38):5392.

44. Chang S, Liu J, Guo S, He S, Qiu G, Lu J, Wang J, Fan L, Zhao W, Che X. HOTTIP and HOXA13 are oncogenes associated with gastric cancer progression. Oncol Rep. 2016;35(6):3577-85.

45. Zhang G, Song W, Song Y. Overexpression of HOTTIP promotes proliferation and drug resistance of lung adenocarcinoma by regulating AKT signaling pathway. Eur Rev Med Pharmacol Sci. 2017;21:5683-90.

46. Cheung WK, Zhao M, Liu Z, Stevens LE, Cao PD, Fang JE, Westbrook TF, Nguyen DX. Control of alveolar differentiation by the lineage transcription factors GATA6 and HOPX inhibits lung adenocarcinoma metastasis. Cancer Cell. 2013;23(6):725-38.

47. Dhanasekaran SM, Balbin OA, Chen G, Nadal E, Kalyana-Sundaram S, Pan J, Veeneman B, Cao X, Malik R, Vats P. Transcriptome meta-analysis of lung cancer reveals recurrent aberrations in NRG1 and hippo pathway genes. Nat Commun. 2014;5:5893

Ready to submit your research? Choose BMC and benefit from

- fast, convenient online submission

- thorough peer review by experienced researchers in your field

- rapid publication on acceptance

- support for research data, including large and complex data types

- gold Open Access which fosters wider collaboration and increased citations

- maximum visibility for your research: over $100 \mathrm{M}$ website views per year

At $\mathrm{BMC}$, research is always in progress.

Learn more biomedcentral.com/submissions 